\title{
Nitrate vulnerability assessment of aquifers
}

\author{
Birgitte Hansen $^{1} \cdot$ Torben O. Sonnenborg $^{2} \cdot$ Ingelise Møller $^{1} \cdot$ Jens Demant Bernth $^{3}$. \\ Anne-Sophie Høyer ${ }^{1}$ - Per Rasmussen ${ }^{2}$ Peter B.E. Sandersen ${ }^{1}$ - Flemming Jørgensen ${ }^{1}$
}

Received: 31 March 2016/Accepted: 21 May 2016/Published online: 11 June 2016

(c) The Author(s) 2016. This article is published with open access at Springerlink.com

\begin{abstract}
Protection of groundwater against nitrate has a high priority in a country like Denmark with intensive agricultural production and with drinking water production based on groundwater. This paper presents a Site-specific Concept for Aquifer Nitrate Vulnerability Assessment (SCANVA) aimed at protecting groundwater resources. SCANVA is a qualitative dynamic concept adjusted to the specific study area depending on the hydrogeological and geochemical conditions. It comprises a synthesis of very detailed site-specific geological, geophysical, hydrogeological and chemical data, and a definition of nitrate vulnerability founded on redox conditions in the ground. Data are used to interpret the geological architecture of the subsurface, the groundwater flow and the geochemical groundwater conditions. These interpretations are integrated to assess nitrate vulnerability of the aquifers in three dimensions and identifying nitrate-vulnerable zones. The paper demonstrates the practical use of the concept in a Danish intensive agricultural area with a glacially formed
\end{abstract}

This article is a part of a Topical Collection in Environmental Earth Sciences on "Groundwater Vulnerability", edited by Dr. Andrzej Witkowski.

\section{Birgitte Hansen}

bgh@geus.dk

1 Department of Groundwater and Quaternary Geology Mapping, Geological Survey of Denmark and Greenland (GEUS), C.F. Møllers Allé 8, Bygn. 1110, 8000 Århus C, Denmark

2 Department of Hydrology, Geological Survey of Denmark and Greenland (GEUS), Øster Voldgade 10, 1350 Copenhagen K, Denmark

3 Department of Soil Pollution and Groundwater, Orbicon A/S, Jens Juuls Vej 16, 8260 Viby, Denmark landscape. Glaciotectonic has led to a high geological heterogeneity and very complex composition of thrusted and folded layers, which to a large extent affect the nitrate vulnerability of the aquifers. SCANVA can be directly applied to specific hydrogeological conditions anywhere with intensive $\mathrm{N}$ loss from agriculture, a groundwaterbased drinking water supply, nitrate reduction in the ground and glacially dominated landscapes and deposits. Potentially, the concept might also be adapted to other specific substances, dominating geochemical processes, and geological settings.

Keywords Nitrate vulnerability - Geochemical redox conditions $\cdot 3 \mathrm{D}$ geology $\cdot$ Groundwater mapping

\section{Introduction}

Protection of groundwater is of intrinsic global importance due to its many uses including as drinking water, in industrial and agricultural production, and because of its environmental value for groundwater-dependent ecosystems such as wetlands and rivers. In the European Union (EU), about $75 \%$ of the residents depend on groundwater for their water supply (European Communities 2008). In many countries throughout the world, an adequate fresh water supply has become a critical issue for a growing population and for increasing industrial production in a changing climate (Thomsen et al. 2013).

The Danish water supply is entirely based on lightly treated groundwater, and protection of groundwater consequently has a high priority. At the same time, Danish farming is one of the most intensive in the world and is threatening the groundwater resources with leaching of nitrate and other contaminants. Numerous waterworks and 
wells have been closed during the last 30 years because of nitrate pollution (Danish Economic Councils 2015), and approximately $19 \%$ of the Danish area has been classified as nitrate-vulnerable groundwater abstraction areas (Danish Environmental Portal 2015).

Both European policies (The Nitrates Directive, 1991/696/EC; The Water Framework Directive, 2000/60/ EC; and The Groundwater Directive, 2006/118/EF) and national Danish legislation aim to protect groundwater resources and surface waters from the effect of $\mathrm{N}$ loss to the environment, and several national political action plans have been successfully implemented since 1985 (Dalgaard et al. 2014; Hansen et al. 2011, 2012). A national groundwater mapping programme has been carried out since 1998 to ensure optimal protection of present and future drinking water resources. The overall strategy of groundwater vulnerability mapping in Denmark has been described by (Thomsen et al. 2004) and (Thomsen and Søndergaard 2007) and involves approximately the $40 \%$ $\left(17,476 \mathrm{~km}^{2}\right)$ of the total Danish land area that is classified as particularly valuable for groundwater abstraction. The groundwater mapping is directly paid by the consumers via an additional 0.09 euros per cubic metre of water. Local groundwater protection plans are carried out in nitrate action zones in order to protect drinking water resources from nitrate pollution.

Groundwater nitrate vulnerability is here defined as the sensitivity of an aquifer to contamination by nitrate depending on the redox conditions in the aquifer and the overlying geological layers. Groundwater vulnerability assessments are a means to synthesise complex hydrogeological information into a form useable by planners, decision- and policy-makers, geoscientists, and the public. The term 'aquifer pollution vulnerability' was invented by Margat (1968), and subsequently given a working definition in the mid-1980s by the US Environmental Protection Agency (EPA), WHO, and the Pan American Health Organization (PAHO) by developing the models called DRASTIC and GOD (Foster et al. 2013). Internationally, the types of methods used to assess vulnerability can be divided into three categories (Liggett and Talwar 2009): (1) index methods, e.g. DRASTIC, GOD, EPIC, (2) statistical methods, e.g. logistic regression, and (3) process methods based on groundwater models, e.g. SAAT/SWAT, MODFLOW and FEFLOW (Sonnenborg et al. 2015). These different methods for assessment of vulnerability have been implemented and extended to specific conditions in many countries (e.g. Sinan and Razack 2008), and all aim to assess the intrinsic geological aquifer vulnerability.

This paper presents a Site-specific Concept for Aquifer Nitrate Vulnerability Assessment named SCANVA. It consists of interpretations of very detailed site-specific hydrogeological measurements based on 3D geological and groundwater modelling that integrates groundwater redox geochemistry. SCANVA is a qualitative dynamic concept adjusted to the specific study area, depending on the hydrogeological and geochemical conditions. SCANVA is directly adaptable to hydrogeological conditions with intensive $\mathrm{N}$ loss from agriculture, groundwater-based drinking water supply, nitrate reduction in the ground and glacially dominated landscapes and deposits. The usability of the SCANVA concept under Danish hydrogeological conditions with a high agricultural $\mathrm{N}$ impact will be demonstrated and will be discussed for a specific catchment area where protection of current groundwater resources is in focus.

\section{Methods}

\section{Definition of nitrate vulnerability of aquifers}

The ability of the aquifer to remove nitrate by microbial oxidation mainly depends on the concentration of the driven reductants: pyrite and organic matter (Appelo and Postma 2005). Nitrate reduction by organic matter, also called denitrification, is a well-known process in aquifers. In addition, nitrate reduction by pyrite oxidation in aquifers has been widely reported also in several Danish studies (Postma et al. 1991; Appelo and Postma 2005; Jørgensen et al. 2009).

The transition between nitrate-containing aerobic sediments and nitrate-free anaerobic sediments with an intact content of reducing solid substances is defined as the redox interface (Hansen and Thorling 2008; Figs. 1, 2, green lines). Geochemically, the redox interface slowly moves downward in sandy layers by $0.01 \mathrm{~mm}$ to $10 \mathrm{~cm}$ per year as the reductants are oxidised by oxygen and nitrate (Postma et al. 1991). The velocity of the downward movement of the redox interface depends on (1) the reactive content of nitrate-reducing matter; (2) the propagation of oxygen and leaching of nitrate from the surface; (3) the water flow and groundwater recharge; and (4) reaction kinetics.

The sulphate content in groundwater is related to the redox conditions due to both pyrite oxidation and sulphate reduction. Sulphate is formed when pyrite embedded in the sediments oxidises and nitrate reduces at the redox interface:

$\mathrm{FeS}_{2}+3 \mathrm{NO}_{3}^{-}+\mathrm{H}_{2} \mathrm{O} \rightarrow 3 / 2 \mathrm{~N}_{2}+2 \mathrm{SO}_{4}^{2-}+\mathrm{FeOOH}+\mathrm{H}^{+}$

However, there can be several other sources of sulphate in groundwater, especially in coastal areas where the groundwater may also be affected by the high sulphate content of seawater either from recent or past transgressions of the sea or by salt water intrusion. 


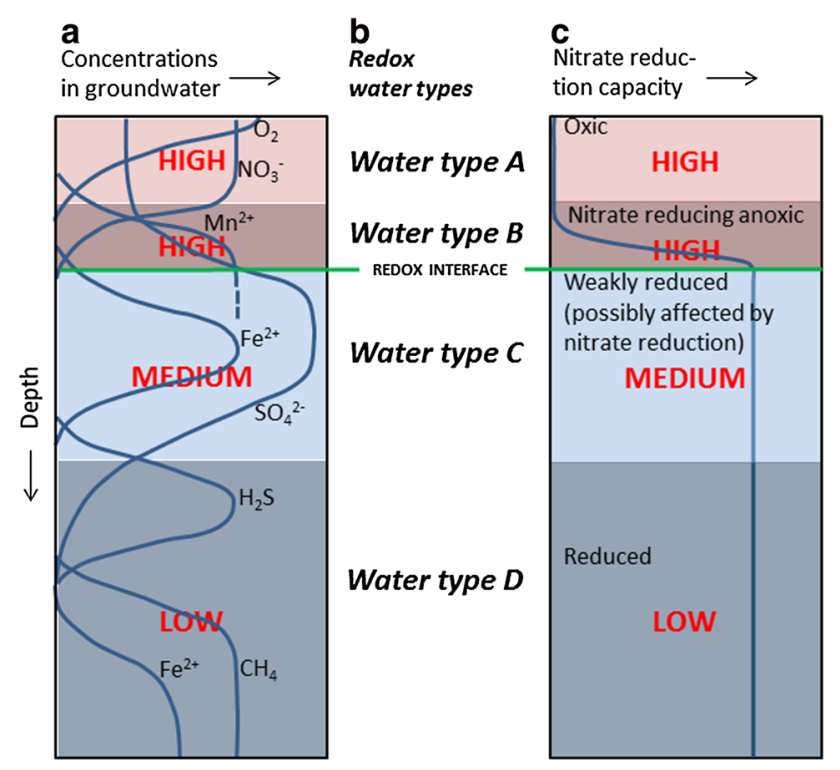

Fig. 1 Definition of high, medium and low nitrate vulnerability of aquifers based on a sequence of reduction processes as displayed in a groundwater chemistry modified from Appelo and Postma (2005), b the redox water types, and c nitrate reduction capacity and redox conditions in the sediment. Green line is the redox interface

The changes in groundwater chemistry in a sequence of different redox environments with increasing depths, when pyrite oxidation is driving nitrate reduction, are schematically shown in Fig. 1a [modified from Appelo and Postma (2005)]. The redox water types from A to D shown in Fig. $1 b$ are defined based on these different redox environments. The reduction capacity of the sediment-also in a sequence of different redox environments with increasing depths-is illustrated in Fig. 1c. The oxic zone (redox water type A) is dominated by the appearance of oxygen and nitrate in the groundwater and a low nitrate reduction capacity of the aquifer sediment. In the nitrate-reducing anoxic redox zone (redox water type B), the oxygen has disappeared and nitrate is undergoing reduction, while manganese is appearing as a reaction product. The extent of the nitrate-reducing anoxic zone varies, and probably always exists on a microscopic scale (Appelo and Postma 2005). The upper part of the weakly reduced zone might be affected by the appearance of the nitrate reduction products $\mathrm{Fe}^{2+}$ and sulphate (redox water $\mathrm{C}$ ), while the deeper parts are affected by sulphate reduction and the disappearance of $\mathrm{Fe}^{2+}$ and sulphate (redox water D). In the reduced zone, the reduction capacity of the sediment is intact at a maximum level. The deepest reduced zone is dominated by the appearance of $\mathrm{H}_{2} \mathrm{~S}$ and methane.

We define specific nitrate vulnerabilities of aquifers based on the redox conditions in the aquifer and overlying geologic layers, as illustrated in Fig. 1. The redox conditions of the aquifer are used to define low, medium and high nitrate vulnerabilities of the aquifers under consideration, as shown in Fig. 1.

An aquifer with oxic or nitrate-reducing anoxic redox conditions is defined as an aquifer with high nitrate vulnerability. Often, only the upper part of the aquifer is affected, but the whole aquifer is considered to have high nitrate vulnerability.

A weakly reduced aquifer with chemical signs of depletion of the nitrate reduction capacity is defined as an aquifer with medium nitrate vulnerability. The chemical

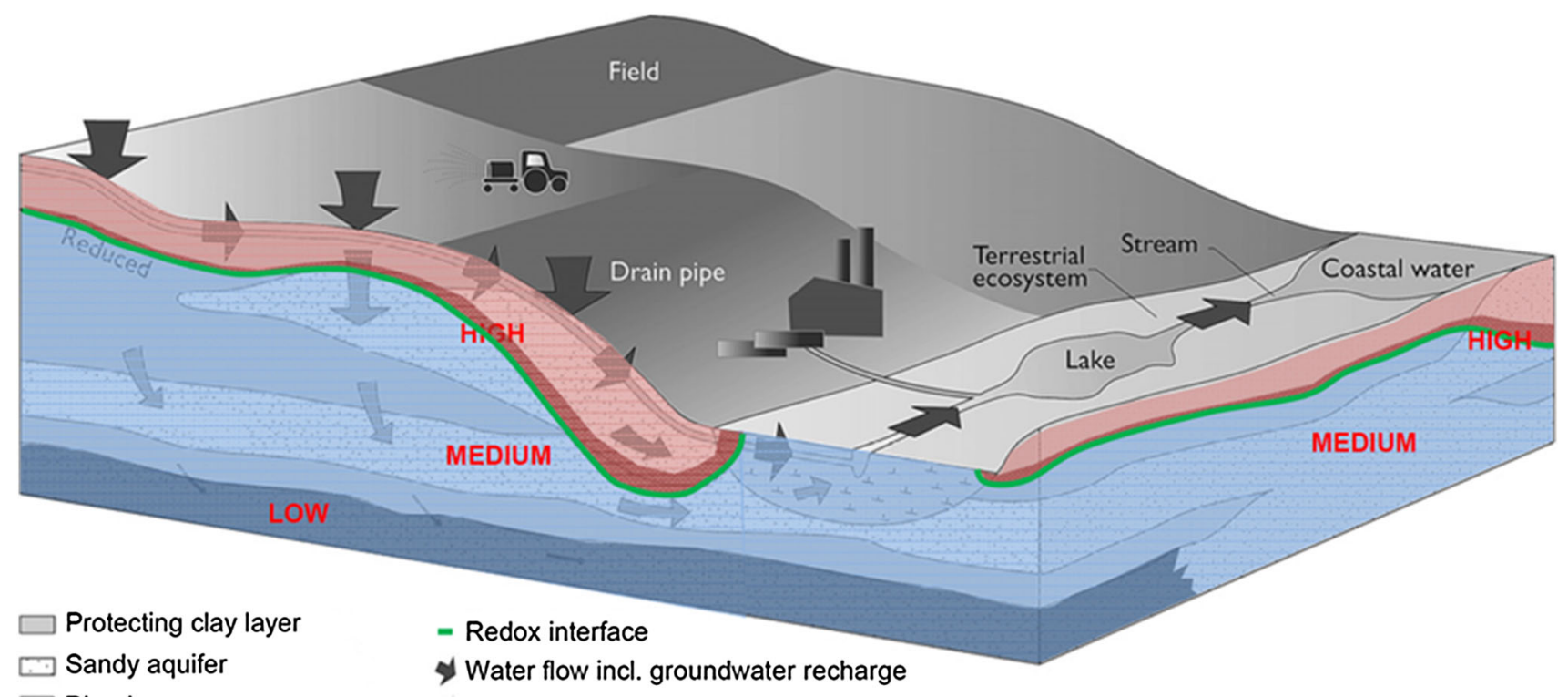

Riparian area

Fig. 2 Illustration of high, medium and low nitrate vulnerabilities of aquifers. Colours of the soil layers show the redox conditions defined in Fig. 1 Modified from Dahl et al. (2007) 
signs could be increasing sulphate concentrations due to pyrite oxidation. This might only occur in the upper part of the aquifer, but the whole aquifer is classified as having medium nitrate vulnerability. The aquifer is at risk of pollution with nitrate in the near future because of depletion of the nitrate reduction capacity.

An aquifer with reduced conditions throughout the whole aquifer is defined as having low nitrate vulnerability.

High, medium and low nitrate vulnerabilities are illustrated in the cross section in Fig. 2 for three sandy aquifers with repeating protecting clay layers. The green line is the redox interface separating oxic and nitrate-reducing anoxic zones from the reduced parts of the aquifer. The deep aquifer is well protected and has therefore low nitrate vulnerability. The middle aquifer is partly protected, the redox interface is close to the upper limits of the aquifer, and therefore, the aquifer has medium nitrate vulnerability. The near-surface aquifer is poorly protected from nitrate leaching and has therefore high nitrate vulnerability.

\section{Definition of nitrate-vulnerable zones}

We define nitrate-vulnerable zones as the areas where groundwater recharge is positive and where the aquifers in focus have medium or high nitrate vulnerability. In practice, it means that areas with upward groundwater flow or discharge of groundwater to rivers or wetland are not included in nitrate-vulnerable zones. Thus, the final delineation of nitrate-vulnerable zones is areas with positive groundwater recharge as shown by the groundwater modelling, and high and medium nitrate-vulnerable aquifers.

\section{Protecting clay layers}

The SCANVA concept relies to a large extent on the abilities of clay layers to protect groundwater from nitrate pollution.

The capacity of the clay layers to protect the groundwater quality of the aquifers depends on various factors, such as: (1) the nitrate reduction capacity, e.g. the content of pyrite, (2) the lithology of the protecting clay layers, e.g. structure and consistency, and (3) the thickness of the protecting reduced clay layers. The protection capacity of the clay layer varies spatially and is especially sensitive to geological heterogeneities such as those caused by glaciotectonic deformation.

\section{SCANVA}

The hierarchical structure of SCANVA for assessment of Aquifer Nitrate Vulnerability is shown in Fig. 3. The detailed groundwater mapping disciplines-3D geological modelling, hydro-geochemical modelling and groundwater modelling - are shown by the blue boxes. Three-dimensional geological modelling determines the overall framework. From the 3D geological model, geological units are identified which are both used in the hydro-geochemical model and in the groundwater model. This detailed groundwater mapping is based on dense geophysical data, borehole data, groundwater chemical analyses, hydraulic heads and stream discharge. The analyses and interpretations of the relatively large amount of data are done by different advanced modelling methods and tools.

Knowledge and key information from the detailed groundwater mapping (blue boxes) are extracted in order to assess the nitrate vulnerability. This is done by geochemical redox interpretation, protecting clay layer modelling, aquifer layer modelling and the groundwater recharge modelling as shown by the white boxes in Fig. 3 .

Local site-specific information about the geochemical and hydrogeological conditions is used to assess the nitrate vulnerability of the aquifers (green box in Fig. 3). More specifically, local site-specific geochemical redox conditions of the aquifer are used to evaluate the nitrate protection capacity of the aquifer and the protecting clay layer above the aquifer. The final assessment of nitrate vulnerability constitutes a synthesis of knowledge about the geochemical redox conditions of the aquifer and the ability of the clay layers to protect the aquifers from nitrate pollution.

The final step in SCANVA is the delineation of nitratevulnerable zones (red box in Fig. 3) which is based on the nitrate vulnerability assessment of the aquifers and the modelled groundwater recharge to the aquifer.

The SCANVA results on nitrate-vulnerable zones are used in the further process of groundwater protection. Nitrate action zones are delineated within the nitrate-vulnerable zones where the actual agricultural nitrate leaching has to be lowered in order to meet the demand of the legislation.

\section{Materials}

\section{Study area}

The usability of SCANVA under Danish hydrogeological conditions will be demonstrated in a specific catchment area where protection of current groundwater resources is ongoing. This study area is situated just north of the Danish-German border in the south-western part of the Jutland peninsula (Fig. 4). The size of the area is $293 \mathrm{~km}^{2}$. It has been delineated according to where geophysical SkyTEM data are available in order to demonstrate assessment of nitrate vulnerability in an area with a high data resolution. The area has a coastal temperate climate, 


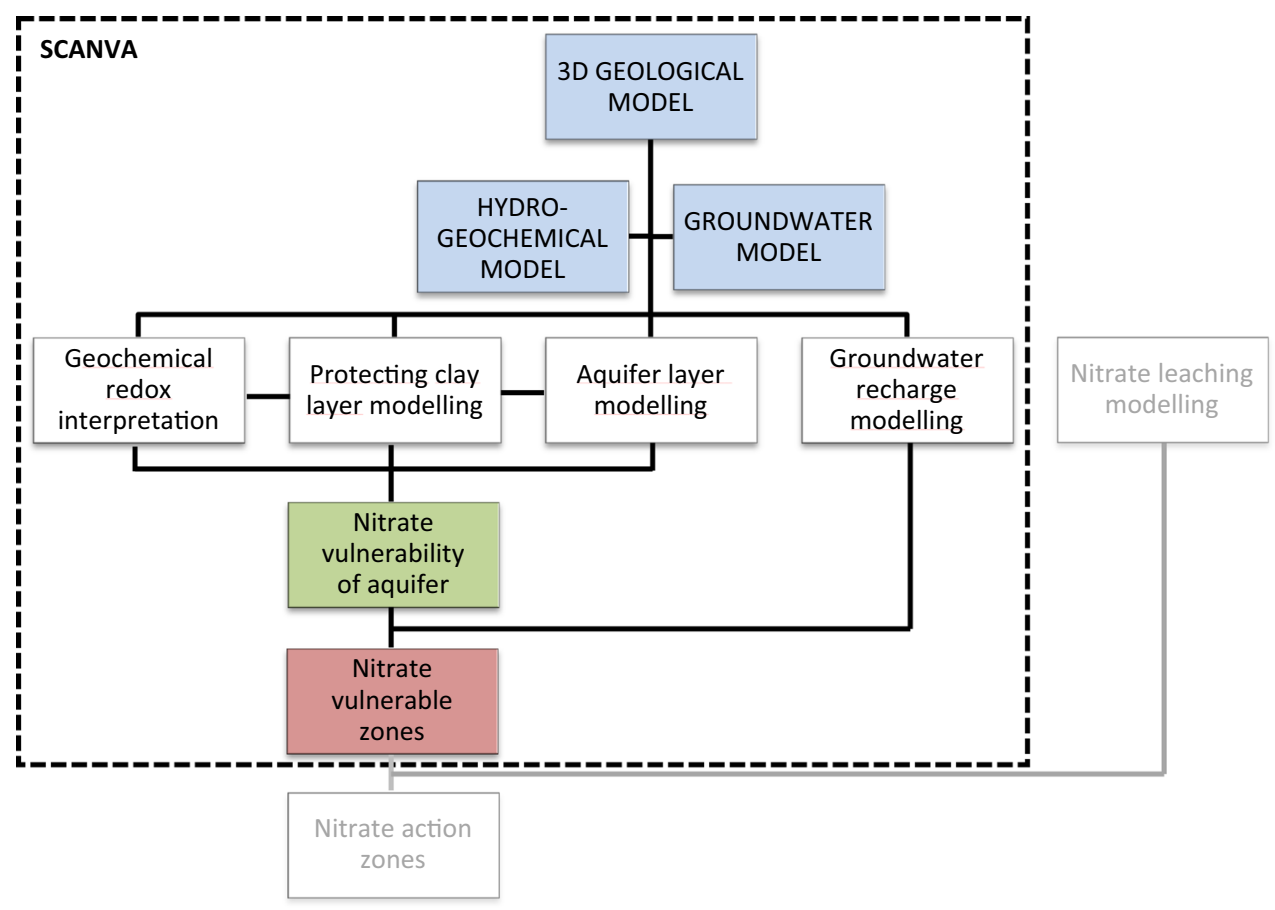

Fig. 3 Hierarchic diagram of the components of the Site-specific Concept for Aquifer Nitrate Vulnerability Assessment called SCANVA. In the further process of groundwater protection, nitrate action zones are delineated based on the risk from nitrate leaching (grey colours)

an average precipitation of $1000 \mathrm{~mm}$ per year and a groundwater recharge of approximately $390 \mathrm{~mm}$ per year (Danish Nature Agency 2014). It is a rather flat nearcoastal area composed of the remaining heights (up to $62 \mathrm{~m}$ above sea level) of a Saalian glacially formed landscape surrounded by outwash plains and Holocene marshland (Jørgensen et al. 2015).

A large part of the area is categorised as particularly valuable groundwater abstraction areas for drinking water production, which means that nitrate vulnerability assessment should be performed by the Danish authorities. The 15 public water supplies in the area had a total allowable abstraction rate of 2.7 million $\mathrm{m}^{3}$ in 2013 . The primary land use in the study area is agriculture (approx. $78 \%$ ). The average nitrate leaching in the period 2009-2012 has been estimated to vary from 25 to more than $100 \mathrm{mg}$ nitrate/l (Danish Nature Agency 2014).

\section{The 3D geological model}

The first of the three elements of the detailed groundwater mapping (Fig. 3) is the 3D geological model constructed using primary geophysical data and borehole data.

\section{Geophysical and borehole data}

The main geophysical dataset in the study area was acquired with the helicopter-borne transient electromagnetic method, SkyTEM (Sørensen and Auken 2004). The SkyTEM survey was carried out in 2009 and includes 1750 line $\mathrm{km}$ collected with a mean line spacing of $166 \mathrm{~m}$, and an investigation depth of 220-280 m (see Fig. 4). The data were processed according to the recommendations in Auken et al. (2009) and were inverted using a spatially constrained inversion algorithm (Viezzoli et al. 2008).

The geophysical data also include a seismic survey consisting of $29.5 \mathrm{~km}$ high-resolution seismic lines and approximately $316 \mathrm{~km}$ oil-seismic lines with a deeper target $(>100 \mathrm{~m})$. The high-resolution seismic lines were acquired by Rambøll in 2010, using the vibroseismic method (van der Veen et al. 2001). The conventional oilseismic data have been extracted from the archives at the Geological Survey of Denmark and Greenland acquired between 1978 and 1992 (Fig. 4).

Lithological borehole information from 3674 boreholes in the study area was extracted from the National Danish borehole database, Jupiter (www.geus.dk). Most of the boreholes are shallow water abstraction wells, and only about $2 \%$ are deeper than $100 \mathrm{~m}$.

\section{Interpretations and modelling}

A 3D geological model was constructed by the use of three different modelling methodologies: clay fraction, stochastic, and cognitive layer modelling, each carefully selected 


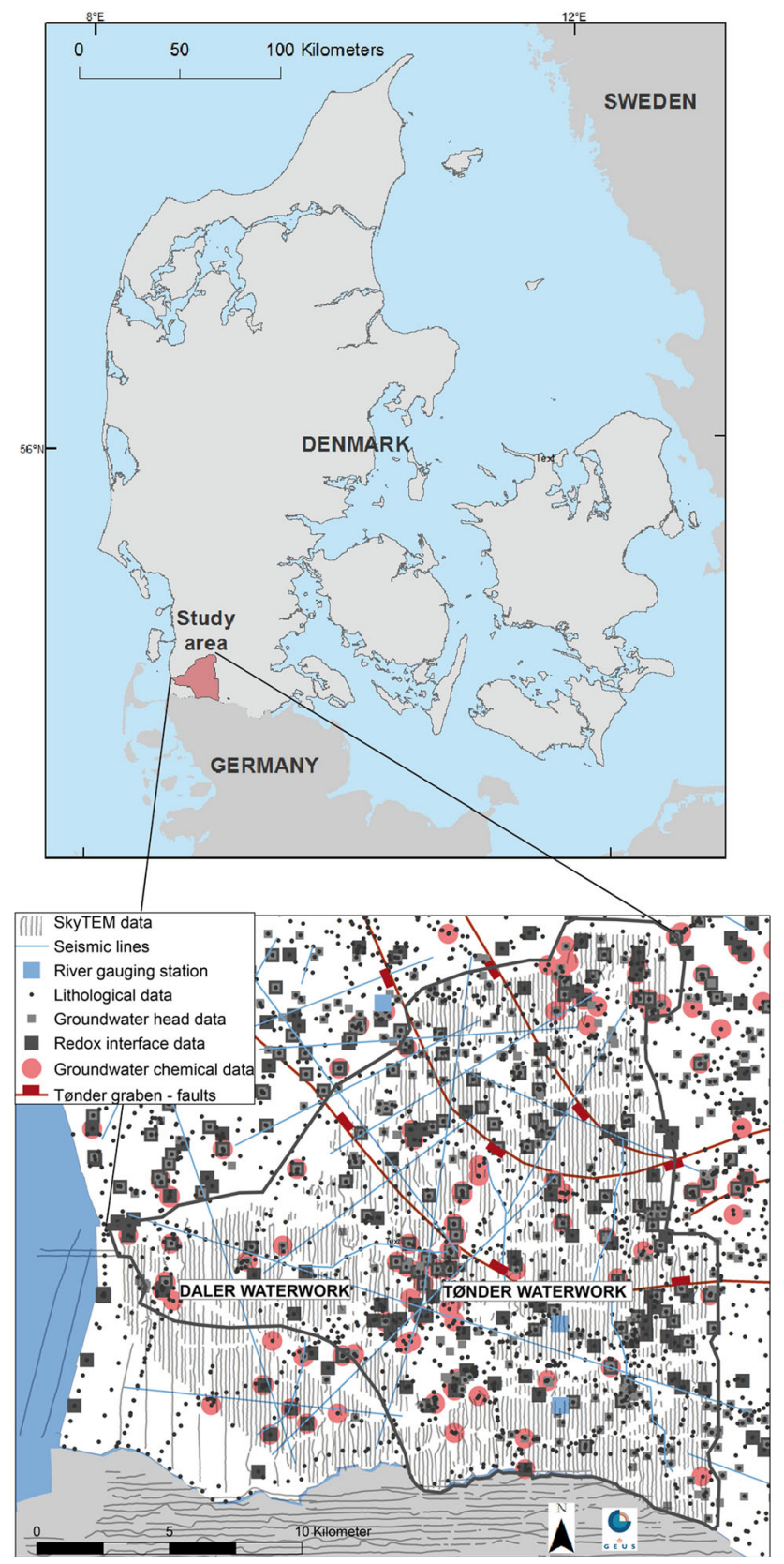

Fig. 4 Top overview map of Denmark and the study area. Bottom map of the location of the study area, data points, the Tønder graben, and the waterworks called Daler and Tønder

to optimise the outcome in subvolumes of the model as described in Jørgensen et al. (2015). The result is a voxel model consisting of 168 layers with voxels of $100 \times 100 \times 5 \mathrm{~m}$ and a total of 17 mill. voxels. The 3D geological model was constructed using the software GeoScene3D (I-GIS 2014).

Figure 5 shows a conceptual sketch of the geological model. Sandy aquifers are present in deposits of both Quaternary and Neogene age. The Quaternary aquifers consist of a sandur, a glaciotectonic complex and a number of buried valleys, and below, the Neogene aquifers consist of Miocene sandy layers. The primary aquifers for drinking water abstractions are found in the glaciotectonic complex, and abstraction depths vary from 15 to about $90 \mathrm{~m}$ below soil surface. Overlying clay layers are to a greater or lesser extent protecting the sandy aquifers in the glaciotectonic complex from nitrate leaching and other pollutants. The thickness of the clay layers varies from 0 to just above $30 \mathrm{~m}$.

\section{The groundwater model}

The second of the three elements of the detailed groundwater mapping (Fig. 3) is the groundwater model based on hydraulic head and stream discharge data as well as the 3D geological model.

\section{Data}

The model is driven by a dataset on root zone percolation from the National Water Resources Model (Henriksen et al. 2003) representing the period 1991-2010. Groundwater modelling is carried out on the basis of measurements of stream discharge at three permanent stations and hydraulic heads from 604 boreholes downloaded from the Jupiter database (Fig. 4). Hydraulic data from 108 of the boreholes are from campaign measurements in 2013, and $95 \%$ of all the hydraulic heads are from well screens located no deeper than $50 \mathrm{~m}$ below sea level. Groundwater abstraction from 796 wells in the model area is included. The total average abstraction equalled 12.5 mill. $\mathrm{m}^{3}$ per year. The 15 largest waterworks produced 2.7 mill $\mathrm{m}^{3}$ per year (2012 data), while the rest was primarily abstracted for irrigation and secondarily for industrial purposes.

\section{Boundary conditions}

The top of the model is defined by a highly accurate digital laser elevation model. The bottom of the model is defined by the top Paleogene surface. The boundaries to the north and south are considered as flow lines and specified as noflow boundaries. To the east, prescribed constant head boundaries are used. Towards the west, the coast line is defined as a constant head boundary for the top layers. At deeper layers, a no-flow boundary that follows the saltwater/freshwater interface is applied, and freshwater is assumed to not mix with the saltwater. This boundary is modelled on the basis of SkyTEM data where resistivities below 20-30 $\Omega \mathrm{m}$ in areas with sandy formations are assumed to indicate high salinity. 
Fig. 5 Conceptual sketch of the geology in the study area. Solid dashed lines are the Tønder Graben faults. Sandy units are the red areas, and the clay units are the in brown areas in the Quaternary Glaciotectonic complex and the buried valleys

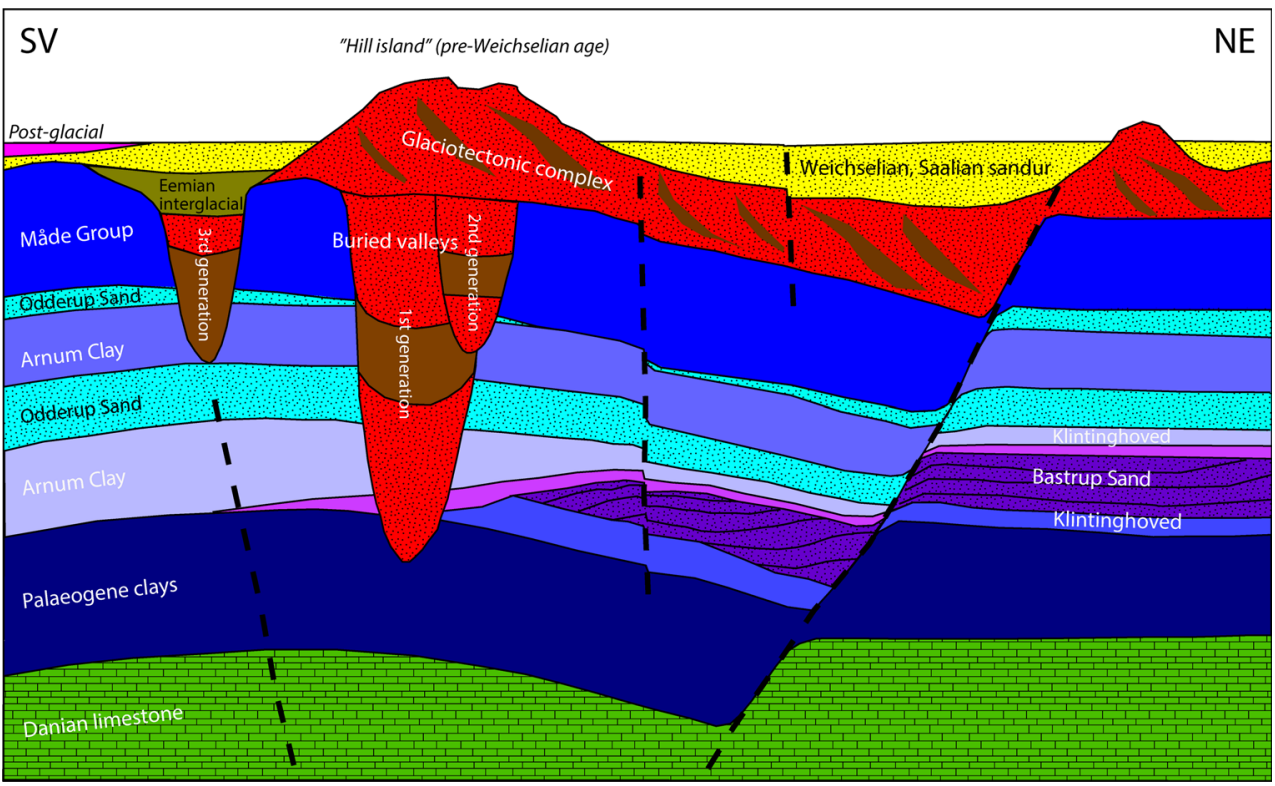

\section{Modelling}

A 3D steady-state groundwater flow model based on MODFLOW 2000 (Harbaugh et al. 2000) was constructed including larger rivers, streams and drains, as described in detail in Rasmussen and Sonnenborg (2015). The 3D geological voxel model was imported into the Hydraulic Unit Flow (HUF) package of MODFLOW 2000. Based on knowledge on primarily grain size and depositional history, the 40 geological units were reduced into eight hydro facies: four Quaternary and four pre-Quaternary units. Each was subdivided into high- and low-permeable sand and high- and low-permeable clay. The parameters of the eight hydro facies of the flow model were estimated using the PEST auto-calibration tool (Doherty 2004) by matching stream discharge and hydraulic head data as described in Rasmussen and Sonnenborg (2015).

\section{The hydro-geochemical model}

The last of the three elements of the detailed groundwater mapping (Fig. 3) is the hydro-geochemical model based on the water chemistry and geochemistry data as well as the 3D geological model.

\section{Water chemistry data}

The groundwater chemistry data were obtained from three different data sources: (1) existing data in the Jupiter database (www.geus.dk), (2) additional nitrate analyses from the local municipality and (3) data from a sampling campaign carried out in 2012-2013. During sampling, online measurements of $\mathrm{pH}$, redox potential, oxygen concentration, temperature and conductivity were performed in order to ensure a high analytical quality and representative groundwater samples. The chemical analyses of the groundwater were performed by professional, certified laboratories.

Groundwater chemistry data in the study area were from a total of 220 monitoring screens in 191 boreholes (Fig. 4). Each borehole has between 1 and 7 monitoring screens. The groundwater chemistry monitoring screens in the boreholes are placed at depths of 2-309 $\mathrm{m}$ below soil surface, the average depth being $45 \mathrm{~m}$ and the median depth $23 \mathrm{~m}$ to the mid-point of the monitoring screen. Groundwater chemical analyses were linked to the geological units in the 3D geological model by the spatial position of the monitoring screens.

\section{Redox interface data}

Sediment colour descriptions from the boreholes were used to evaluate the depth of the redox interface (Hansen and Thorling 2008). In the study area, the redox interface was evaluated in 382 boreholes (see Fig. 4) with sediment colour descriptions following the guidelines in Hansen et al. (2009a, b). Red and brown colours indicate aerobic conditions, while grey colours reflect anaerobic conditions.

\section{Interpretations and modelling}

The general groundwater chemistry was analysed, illustrated and interpreted using different presentation tools as described in Hansen et al. (2015).

The redox interface was modelled as a surface in GeoScene3D by interpolating information on the deepest 
redox interface in 382 wells using inverse distance with a search radius of 2000 and $100 \mathrm{~m}$ cells. The hydro-geochemical modelling was performed as interpretations in 1D depth profiles in three investigation wells and along ten 2D conceptual geological models extracted from GeoScene3D as described in Hansen et al. (2015).

\section{Results}

\section{Geochemical redox interpretations}

\section{Redox water types}

The redox water types for the groundwater samples were determined according to the redox conditions schematically shown in Fig. 1. The criteria shown in Table 1 were used to determine the redox water type in each sample, which is founded on typical values in Danish groundwater (Danish Environmental Protection Agency 2000; Hansen et al. 2009a, b).

The redox water types in 169 groundwater samples from the study area are grouped according to the geological units and the depth of the monitoring point ( $\mathrm{m}$ below soil surface), as shown in Fig. 6. Redox water types A and B, which may contain nitrate, are only found in the Quaternary deposits, and not in the Miocene layers. Approximately 60,31 and $14 \%$ of the sampled groundwater in the near-surface sandur deposits, the glaciotectonic complex and the buried valleys, respectively, have water type A or B. Water samples with reduced water have been found in all types of geological units. This indicates that in the deepest part of the Quaternary aquifers reduced water is always present even if the upper part is oxic, as illustrated in Fig. 2.

Contamination of groundwater with nitrate was limited to the Quaternary deposits in the top approximately $40 \mathrm{~m}$ soil and was found at the greatest depth in the glaciotectonic complex. The groundwater and drinking-water quality standard of $50 \mathrm{mg} / \mathrm{l}$ nitrate was exceeded in approximately 4 and $13 \%$ of the screens in the glaciotectonic complex and the sandur, respectively.

\section{Sulphate and nitrate reduction}

The distribution of the sulphate concentration in the geological units differed significantly and reflected both the different sulphate sources in the area and also the redox conditions in the aquifers (Fig. 1; Table 1). About $25 \%$ of the wells screened in the near-surface sandur deposits, $50 \%$ of the wells screened in the glaciotectonic complex and deep-buried valleys, and $70 \%$ of the monitoring screens in the deep Miocene sediments had water type D with low concentrations of sulphate $(<20 \mathrm{mg} / \mathrm{l})$ and hence had strongly reduced conditions.

The Danish drinking water standard of $250 \mathrm{mg} / \mathrm{l} \mathrm{sul-}$ phate was exceeded in near-surface monitoring screens at depths of less than about $32 \mathrm{~m}$ below soil surface. These high sulphate concentrations were all located in the marsh area close to the sea (Fig. 8a) and can be explained by the influence of seawater. The deepest Miocene monitoring screens ( $>200 \mathrm{~m}$ below sea level) also had higher sulphate concentrations than the shallower monitoring screens in the Miocene. This shows the marine influence from past transgressions of the sea or residual saline water.

The data analysis showed that the near-surface monitoring screens down to $75 \mathrm{~m}$ below sea level with sulphate concentrations in the interval from 20 to $120 \mathrm{mg} / \mathrm{l}$ to some degree might be affected by pyrite oxidation. Sulphate trend analyses by linear regression were performed in 41 of these monitoring screens according to the principles outlined by Hansen et al. (2011) to assess if active pyrite oxidation was taking place. Statistically significant increasing sulphate trends $(p \leq 0.05)$ were found in the central part of the study area in the glaciotectonic complex in abstraction wells at the Tønder and Daler waterworks (Figs. 4, 7, 8a).

Besides nitrate, occurrences of agricultural pesticide residues (mainly metabolites of the herbicide Dichlorbenil) in the groundwater indicate that the aquifers are vulnerable to surface pollution. Figure $8 \mathrm{a}$ shows the occurrences of pesticides in the study area along with sulphate concentrations and trends. It can be seen that in the central part of the study area the aquifers in the glaciotectonic complex are often affected by pesticides. These detections of pesticides coincide to some degree with the location of the abstraction wells with increasing sulphate concentrations.

\section{The redox interface}

The interpolated surface of the redox interface in the study area is shown in Fig. 8b together with observations of nitrate at groundwater monitoring points. The depth to the redox interface in each borehole fluctuated between $<5$ and up to $47 \mathrm{~m}$ below soil surface. The deepest penetration of nitrate into the aquifer tended to coincide with a large depth of the redox interface. Complex hydrogeological conditions often result in several redox interfaces in the same borehole due to many changes in the borehole sediment from red/brown (oxic) to grey (reduced). This indicates non-vertical infiltration in a heterogeneous geological setting. In the areas with very deformed sediments in the glaciotectonic complex, several colour shifts were seen between oxic and reduced conditions in the same boreholes. This phenomenon was observed in 49 of the 382 
Table 1 Criteria for redox-sensitive water chemical species (mg/l) used to define redox water types Modified from Danish Environmental Protection Agency (2000) and Hansen et al. (2009a)

\begin{tabular}{lllll}
\hline Redox water type & Redox conditions & $\mathrm{O}_{2}$ & $\mathrm{NO}_{3}{ }^{-}$ & $\mathrm{Fe}^{2+}$ \\
\hline A & Oxic & $>1$ & & $\leq 0.2$ \\
B & Nitrate-reducing anoxic & $\leq 1$ & $>1$ & \\
C & Weakly reduced (possibly affected by nitrate reduction) & $\leq 1$ & $\leq 1$ & $\leq 1$ \\
D & Strongly reduced & $\leq 1$ & $\leq 1$ & $\leq 20$ \\
\hline
\end{tabular}

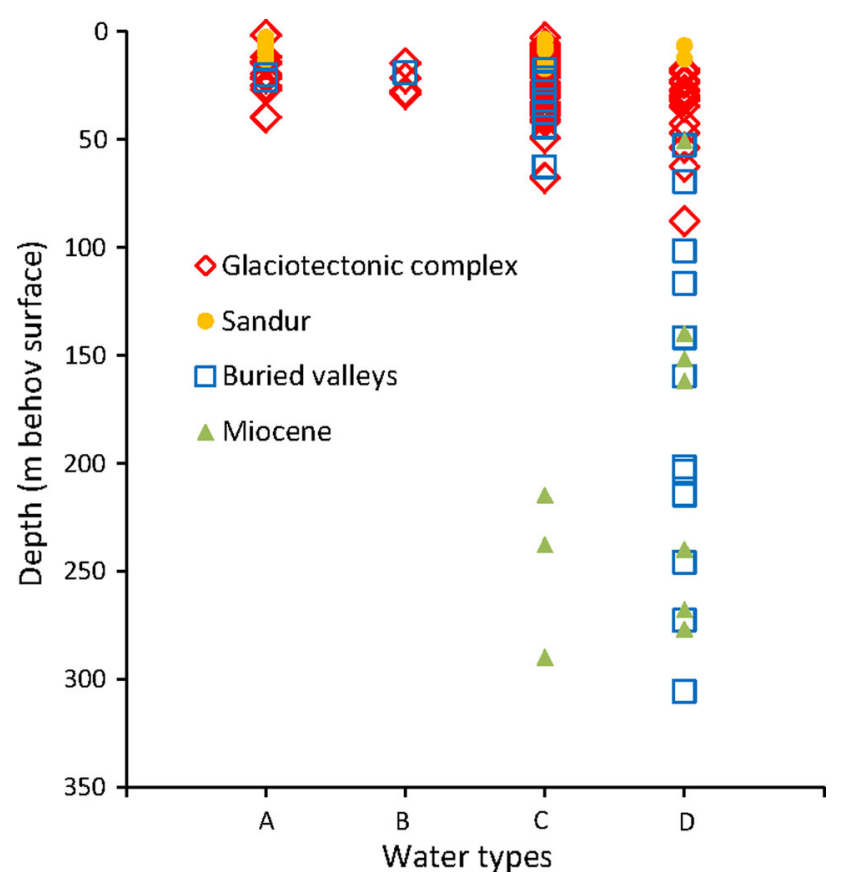

Fig. 6 Redox water types in 169 groundwater samples from the study area grouped according to the geological units and the depth of the top of monitoring point

wells (about $13 \%$ ) used to generate the interpolated map of the deepest redox interface shown in Fig. $8 \mathrm{~b}$.

\section{Aquifer layer modelling}

Primarily, the sand units within the glaciotectonic complex are currently used for drinking water abstraction. Sandy Miocene layers below are often unsuitable for abstraction due to a high content of dissolved organic matter or a high salinity. The groundwater in the upper sandur is disregarded due to contamination with nitrate and other anthropogenic compounds. Hence, the sandy units within the glaciotectonic complex have been defined and demarcated from the geological model. This sandy Quaternary aquifer reaches a maximum depth of $60 \mathrm{~m}$ below sea level, and in the central part of the study area, along the Tønder graben structure (see location on Fig. 4), the maximum thicknesses reach about $90 \mathrm{~m}$ (Fig. 8c).

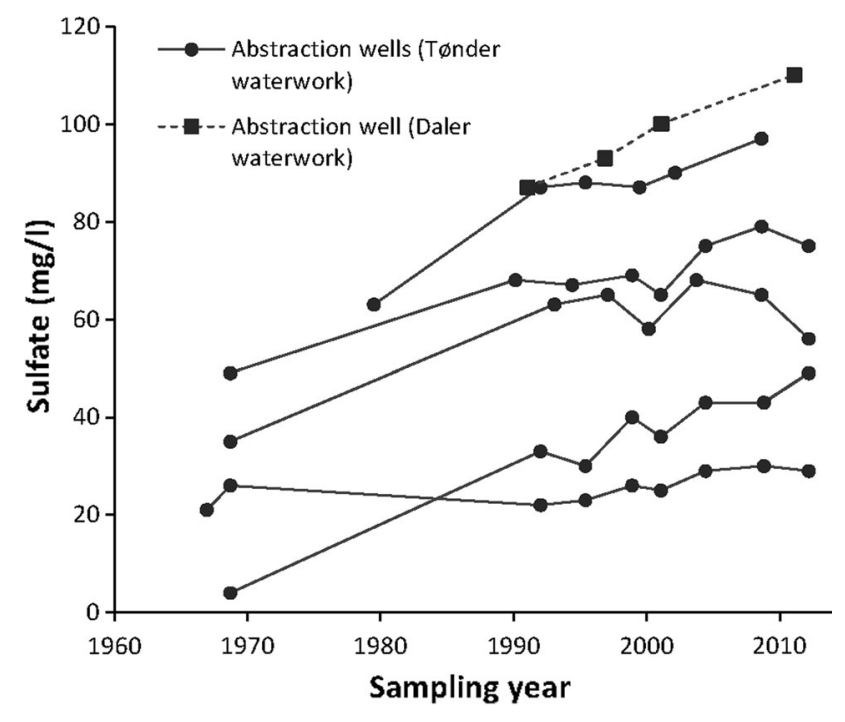

Fig. 7 Drinking water abstraction wells in the study area with statistically significant increasing sulphate concentrations in groundwater according to sampling year. See location of waterworks in Figs. 4 and $8 \mathrm{a}$

\section{Protecting clay layer modelling}

The extent and thickness of the protecting clay above the sandy Quaternary aquifer in the glaciotectonic complex were extracted from the 3D geological model (Fig. 8d). This was done in the 3D geological model by accumulating voxels with a content of more than $50 \%$ clay. Since the voxel layers are $5 \mathrm{~m}$ thick, the resulting clay thickness map was produced with discrete values for each $5 \mathrm{~m}$ (Fig. 8d). The clay thickness varied from $<5 \mathrm{~m}$ to more than $30 \mathrm{~m}$ in the study area.

The clay layer contained a higher degree of spatial information than the geochemical results, and the thickness of the protecting clay layer was therefore given a high priority in the assessment of nitrate vulnerability.

The nitrate reduction capacity of the protecting clay layer was evaluated by analysing the depth and horizontal extent of the redox interface (Fig. 8b) and the thickness of the clay layers (Fig. 8d). In the central part of the study area, there was a tendency for the near-surface redox interface $(<5 \mathrm{~m}$ below surface) to coincide with the 

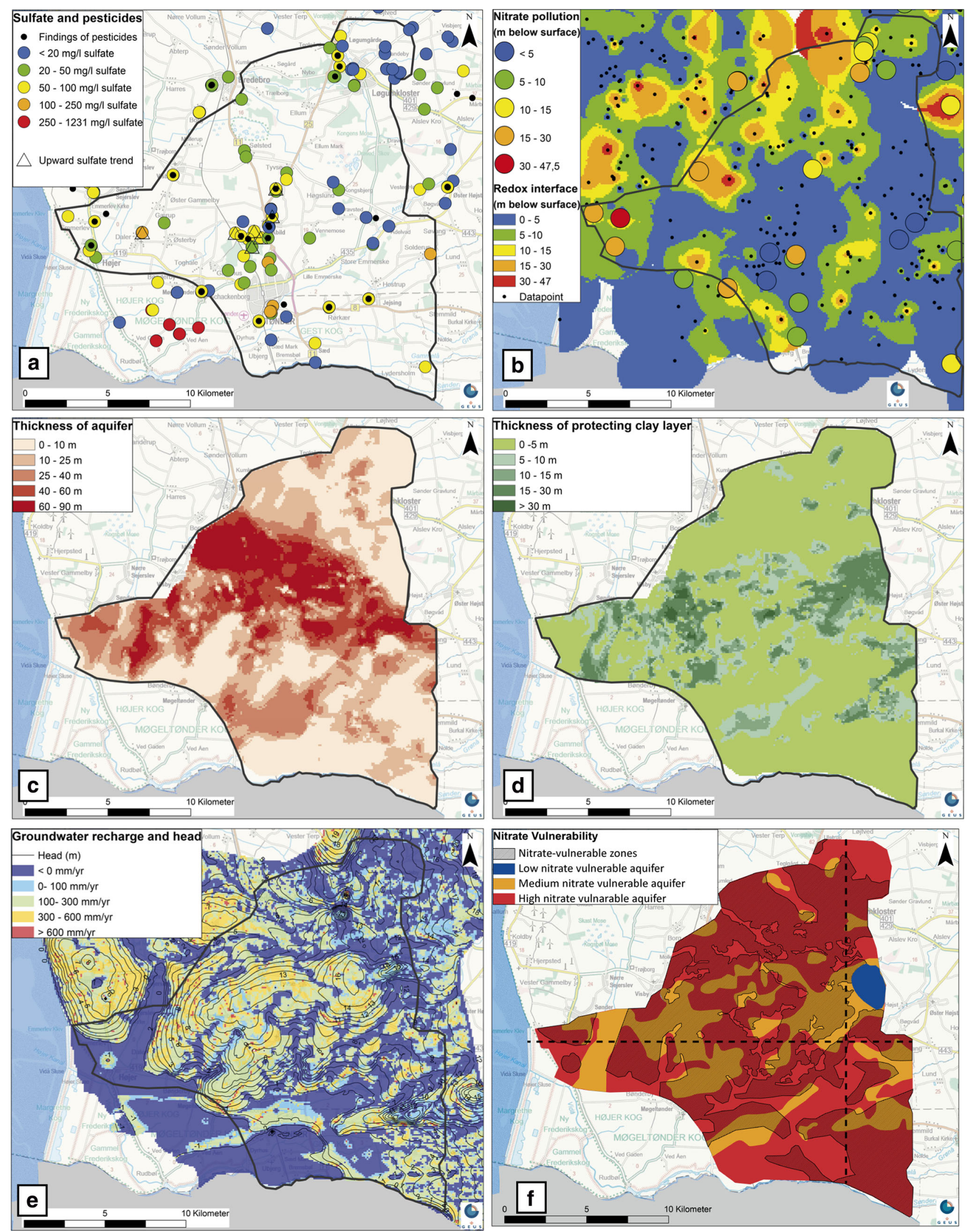
4Fig. 8 Thematic maps from the study area: a sulphate concentrations, sulphate trends and pesticide occurrences, $\mathbf{b}$ the interpolated redox interface and depth of nitrate occurrences, $\mathbf{c}$ thickness of the sandy quaternary aquifer, d thickness of protecting clay layer, e groundwater recharge to the aquifer ( $\mathrm{mm}$ per year) and head ( $\mathrm{m}$ above sea level), and $\mathbf{f}$ final assessment of nitrate vulnerability of the aquifer, and delineation of nitrate-vulnerable zones

relatively thick protecting clay layers $(>15 \mathrm{~m})$. In contrast, in the northern part of the study area the deep redox interface ( $>10 \mathrm{~m}$ below soil surface) appeared to coincide with relatively thin protecting clay layers $(<5 \mathrm{~m})$.

A qualitative assessment of the correlation between clay thickness and the redox interface was performed for the 169 boreholes with usable colour descriptions and based on redox interfaces in the sandy Quaternary aquifer in the glaciotectonic complex and accumulated clay thicknesses in the geological model voxel with the boreholes shown in Fig. 8d. There was an apparent inverse correlation between the protecting clay thickness and the depth of the redox interface, as illustrated in Fig. 9. When the redox interface was close to the surface ( $\leq 5 \mathrm{~m}$ below soil surface) and the nitrate reduction capacity was high, the clay layers were generally thicker (approx. $70 \%$ were thicker than $5 \mathrm{~m}$ ). In contrast, when the redox interface was deeper $(5-30 \mathrm{~m}$ below surface) and the nitrate reduction capacity lower, the clay layers were generally thinner (approx. $40 \%$ were thicker than $5 \mathrm{~m}$ ).

\section{Assessment of nitrate vulnerability}

Local site-specific geochemical redox conditions of the aquifer were used to evaluate the nitrate protection capacity of the clay layer above the aquifer. The final assessment of nitrate vulnerability constitutes a synthesis of knowledge about the geochemical redox conditions of the aquifer and the capacity of the clay layers to protect the aquifers from nitrate pollution.

The SCANVA concept for assessment of nitrate vulnerability was adjusted to specific hydrogeological and geochemical conditions in the study area. Aquifers in the study area were defined to have high nitrate vulnerability if they contained groundwater with redox water type A or B, as shown in Figs. 1 and 2. The data synthesis in the study area showed that a protective clay layer thickness of less than $5 \mathrm{~m}$ gave a high nitrate vulnerability of the aquifers in the study area (Fig. 10).

Aquifers were defined to have medium nitrate vulnerability if they had weakly reduced redox conditions (redox water type C) and signs of nitrate reduction, as shown in Figs. 1 and 2. The data synthesis in the study area showed that a protective clay thickness of between $5 \mathrm{~m}$ and $30 \mathrm{~m}$ gave medium nitrate-vulnerable aquifers. In the study area,

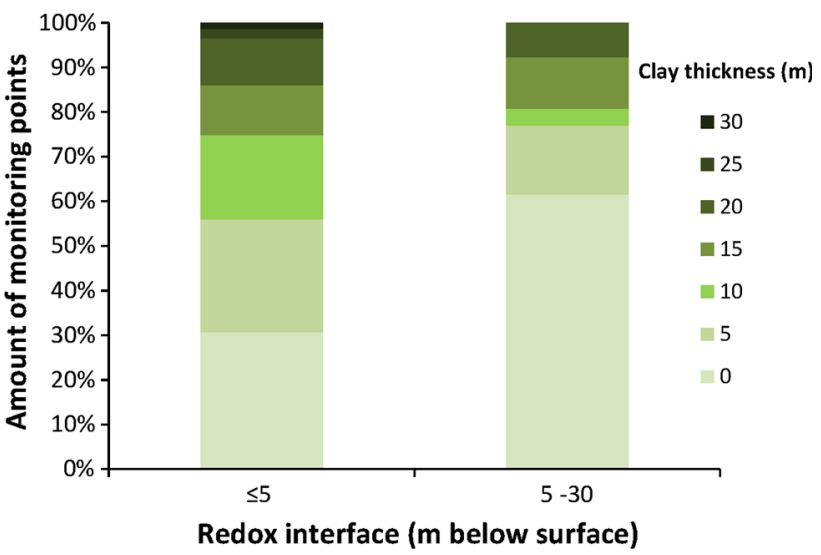

Fig. 9 Thickness of protecting clay layer (m) calculated from the 3D geological model and redox interface based on colour descriptions from 169 boreholes

increasing sulphate concentrations due to nitrate reduction in abstraction wells led to depletion of the nitrate reduction capacity by nitrate reduction and pyrite oxidation (Figs. 7 , 8a). The medium nitrate vulnerability was also evidenced by the occurrence of pesticides, which generally indicate vulnerability to surface pollution.

Aquifers were defined to have low nitrate vulnerability if they had reduced conditions (water type $\mathrm{C}$ or $\mathrm{D}$ ) throughout the aquifer with no signs of nitrate reduction, as shown in Figs. 1 and 2. The data synthesis for this situation in the study area showed that a protective clay layer thickness of more than $30 \mathrm{~m}$ gave a low nitrate vulnerability.

The assessment of the nitrate vulnerability of the aquifers currently used for drinking water abstraction in the study area is shown in Fig. 8f. The assessment integrated the results from the 3D geological modelling, the groundwater modelling and the hydro-geochemical modelling, as shown in Fig. 3. From the detailed groundwater mapping, knowledge and key information could be transferred to interpret the geochemical redox conditions, to model the extent of the aquifer, the protecting clay layers and the groundwater recharge (Fig. 3). The local site-specific geochemical redox conditions of the aquifer were used to evaluate the nitrate protection capacity of the clay layer above the aquifer. The final assessment of nitrate vulnerability was a synthesis of the knowledge about the geochemical redox conditions of the aquifer and the capacity of the clay layers to protect the aquifers from nitrate pollution, defined from the thickness of the protecting clay layers.

The uncertainty relating to the assessment of nitrate vulnerability in the study area was evaluated qualitatively based on the combined data density used in the 3D modelling of the geology, groundwater and hydro-geochemistry (Fig. 4). High-resolution geophysical SkyTEM data almost covered the entire study area, resulting in a relative low 


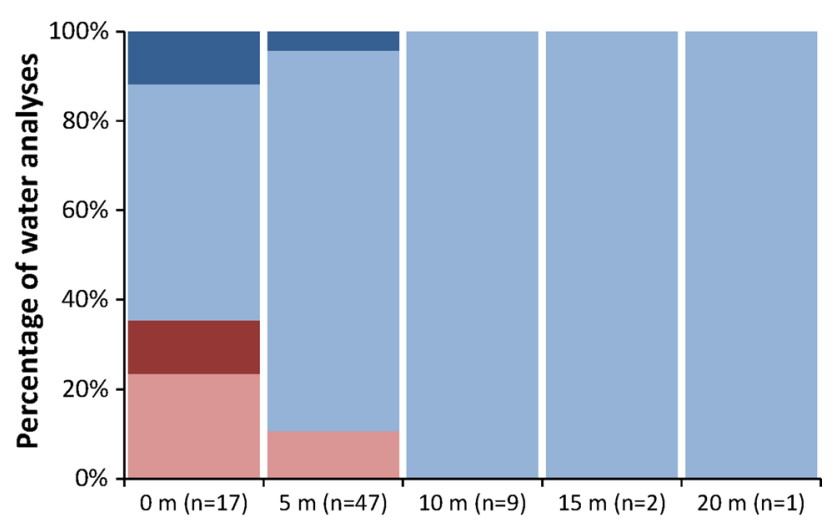

Thickness of protecting clay layer $(\mathrm{m})$

$\square$ Water type $\mathrm{A} \square$ Water type $\mathrm{B} \square$ Water type $\mathrm{C} \square$ Water type $\mathrm{D}$

Fig. 10 Thickness of protecting clay layer $(\mathrm{m})$ calculated from the 3D geological model and the redox water types in 76 monitoring points in the glaciotectonic complex used to assess nitrate vulnerability

uncertainty for the 3D geological model. The groundwater chemistry data density, on the other hand, was unequally distributed geographically and in the geological space, which affected the uncertainty in the hydro-geochemical modelling. The north-western, the central and the southeastern parts had a relatively low data density for groundwater chemistry, but the data coverage of the redox interface from boreholes was relatively high.

Hydro-geochemical interpretations along 2D geological profiles were also performed as part of the final assessment and visualisation of the nitrate vulnerability of the aquifers. Figure 11 shows two examples-a south-north 20-km-long profile, and a west-east $21-\mathrm{km}$-long profile, both with a vertical exaggeration of approximately 32 .

Along the profiles, the uppermost parts of the subsurface consist of thin and patchy Holocene postglacial deposits on top of up to $30 \mathrm{~m}$ thick sandy Quaternary sandur sediments. These nitrate unprotected sandur units have been deposited on top of an up to 130-m-thick glaciotectonic sequence. Several cross-cutting and deep-buried valleys are seen along the profiles. In some parts of the study area, the upper sandy layers in the buried valleys contain valuable drinking water resources with low nitrate vulnerability and good quality. Sandy aquifers with low nitrate vulnerability were also found in older Miocene deposits (e.g. the Bastrup formation, see Fig. 5). However, these Miocene deposits often have a high content of organic matter and a relative high salinity, resulting in a poor drinking water quality.

The aquifers currently used as drinking water resources are found within the glaciotectonic complex illustrated on the profiles in Fig. 11. These aquifers mainly have high or medium nitrate vulnerability. Thus, only a small part of the aquifers in the mid-eastern part of the study area have low nitrate vulnerability. The nitrate protection capacity of the aquitard (clay layer) is therefore relative low. This is primarily due to a high degree of discontinuity of the aquitard as a result of glaciotectonical deformation. The parts of the aquifers in the glaciotectonic complex with high nitrate vulnerability are characterised by thin protecting clay layers $(<5 \mathrm{~m})$.

The medium nitrate vulnerability of the aquifers in the glaciotectonic complex is distinguished by protecting clay layers with an accumulated thickness of 5-30 m (upper brown layers, see Fig. 11). Groundwater in these areas did not contain nitrate. However, in some areas significant and increasing sulphate concentrations are observed or pesticides have been found in the aquifers.

\section{Groundwater recharge modelling}

Results from the 3D groundwater model on groundwater recharge to the Quaternary sandy aquifer in the glaciotectonic complex are shown in Fig. 8e together with the contour map of the groundwater head. In the study area, the groundwater recharge to the aquifers varied from 0 to more than $600 \mathrm{~mm}$ per year. Groundwater discharges (recharge $<0 \mathrm{~mm}$ ) in low-lying wetlands and marshlands and recharges especially in the higher parts in the glacial hills.

\section{Delineation of nitrate-vulnerable zones}

Nitrate-vulnerable zones are defined as areas where groundwater recharge to the aquifer is positive and where the aquifers in focus have medium or high nitrate vulnerability. This means that areas with upward groundwater flow or discharging groundwater to rivers, wetlands and marshland are not included in the nitrate-vulnerable zones. The final delineation of nitrate-vulnerable zones is seen in Fig. 8f.

\section{Discussion}

National $\mathrm{N}$ regulation of agriculture has been implemented in Denmark since 1985, resulting in statistically significant reductions in nitrate concentrations in oxic groundwater and other parts of the environment at the national level (Hansen et al. 2011; Dalgaard et al. 2014). However, there is an additional need at local scale to further strengthen the $\mathrm{N}$ use and agricultural management in order to meet the demands of the legislations (Hansen et al. 2011, 2012). This is the overall purpose of the Danish National Groundwater mapping programme, and the presented concept for assessment of nitrate vulnerability of aquifers. Groundwater protection in Denmark focuses specifically on nitrate due to the severe pressure from intensive agricultural production and availability of knowledge to perform substance-specific vulnerability assessment (Danish 

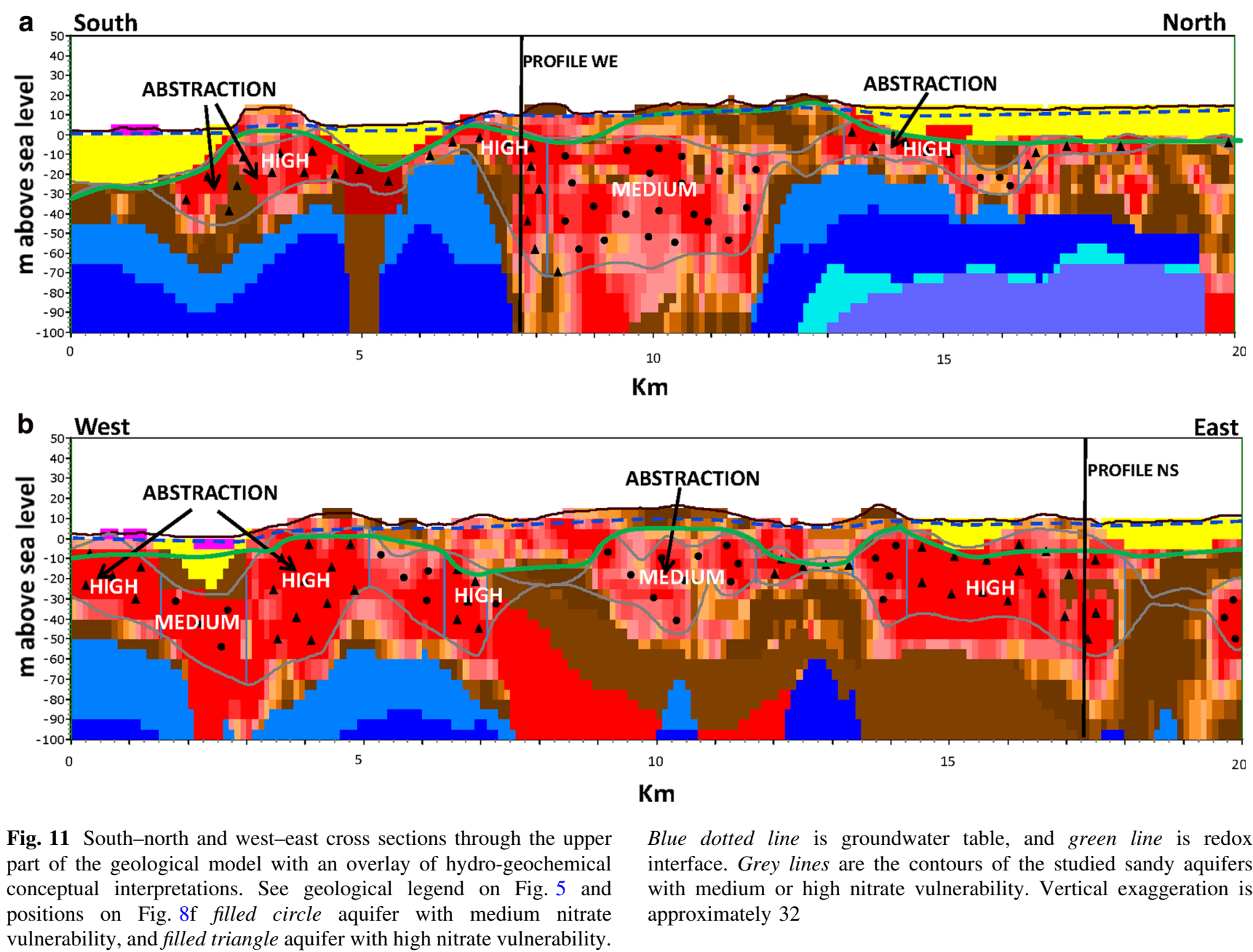

Fig. 11 South-north and west-east cross sections through the upper part of the geological model with an overlay of hydro-geochemical positions on Fig $8 f$ filled circle aquifer with medium nitrate vulnerability, and filled triangle aquifer with high nitrate vulnerability.

Environmental Protection Agency 2000; Hansen et al. 2009a, b).

The SCANVA concept for qualitative assessment of nitrate vulnerability takes the redox conditions and the degradation of nitrate in the aquifer into account. SCANVA is a cognitive assessment tool based on very detailed site-specific hydrogeological data and modelling results that integrate the monitoring results on groundwater quality. The extent of protective clay layers above the aquifer is given a high priority in the final assessment of the nitrate vulnerability of the aquifer as it summarises the most detailed hydrogeological information from the study area extracted from the 3D geological model. The advantage of SCANVA is that it is based on detailed geophysical, geological, hydrological and chemical measurements and interpretations, and that it specifically focuses on nitrate. In its present form, the SCANVA concept is not able to handle vulnerability assessments of other substances, unless the concept is further developed.

Vulnerability of aquifers is defined as "an intrinsic property" that depends on the sensitivity of an aquifer to
Blue dotted line is groundwater table, and green line is redox interface. Grey lines are the contours of the studied sandy aquifers with medium or high nitrate vulnerability. Vertical exaggeration is approximately 32

pollutant pressure from the land surface (Foster et al. 2013; Liggett and Talwar 2009; Vrba and Zaporožec 1994). Groundwater vulnerability can be determined for any point of interest in the subsurface, but vulnerability assessments are typically performed for the water table, uppermost aquifer or a particular well (Liggett and Talwar 2009). In our case, the assessment of nitrate vulnerability was done for the entire Quaternary glaciotectonic complex containing the current drinking water resources from 15 to $90 \mathrm{~m}$ below surface in the study area. It resulted in a delineation of aquifers into low, medium or high nitrate vulnerability. However, if the nitrate vulnerability of near-surface sandy meltwater aquifers (the sandur) had been assessed, the sandur aquifers would have been in the high vulnerability category. Only a small part of the assessed aquifers in the Quaternary glaciotectonic complex had low nitrate vulnerability. This low protective capacity of the clay layers in the study area is properly due to geological heterogeneity caused by glaciotectonic deformation, where the thrusting and folding have caused inconsistencies in the layers (Jørgensen et al. 2015). The low protective capacity of the 
clay layers might also be influenced by neotectonic deformation of the near-surface Quaternary layers caused by deep tectonic movements related to the Tønder graben structure in the area (Sandersen and Jørgensen 2014; Figs. 4, 5). In addition, Sonnenborg et al. (2015) showed that geological features such as buried valleys may shortcircuit otherwise deep, protected aquifers with the surface, resulting in relatively short travel times and hence a high vulnerability of the deeper reservoirs.

A total assessment of uncertainties in vulnerability assessments is a complicated task. Index methods such as DRASTIC, GOD or EPIK in their original formulation do not take uncertainties into account (e.g. Gogu and Dassargues 2000; Armengol et al. 2014). These methods are completely deterministic approaches. Recent studies have introduced uncertainties to the DRASTIC method by applying geostatistical methods to the individual data supporting each of the seven DRASTIC parameters (Armengol et al. 2014; Chen et al. 2013). In this way, they have turned the deterministic DRASTIC method into a stochastic one. This means decision-makers are able to put some degree of confidence into the rating of each DRASTIC parameter leading to the vulnerability map. The presented SCANVA concept incorporates all types of uncertainties, ranging from quantifiable statistical uncertainties to uncertainties that only can be described qualitatively (Refsgaard et al. 2010). Examples include uncertainties in the primary data (geophysical, borehole, water chemistry, etc.), in the geological, groundwater and hydro-geochemical models, and in the final nitrate vulnerability assessment. Although the primary data have quantifiable uncertainties, they may be transferred into uncertainties that can only be described qualitatively-for example, when geophysical data are subject to a cognitive geological interpretation into lithology (Høyer et al. 2015).

In hydrological modelling, it is recognised that geologically related uncertainty will significantly influence the prediction uncertainties, as shown by, e.g. He et al. (2013). Different approaches incorporate geologically related uncertainties using multiple geological models constructed either manually or stochastically (Refsgaard et al. 2012). In SCANVA, the uncertainty is assessed qualitatively by evaluating the data density in the study area used in both $3 \mathrm{D}$ geological, groundwater and hydro-geochemical modelling.

\section{Conclusion}

SCANVA is a qualitative dynamic concept for site-specific aquifer nitrate vulnerability assessments and differs from the commonly used index, statistical and process methods for groundwater vulnerability assessment. The criteria used in SCANVA are adjusted to specific hydrogeological and geochemical conditions in a study area. The concept relies on dense geophysical, geological, geochemical and hydrological measurements. Information on geochemical redox conditions, aquifer and protecting clay layers is used to assess the nitrate vulnerability. The protecting properties of the clay layers have been given the highest priority in the assessment due to a high degree of spatial information compared to the geochemical results. The SCANVA concept can directly be implemented and extended to specific conditions in study areas with intensive $\mathrm{N}$ loss from agriculture, groundwater-based drinking water structure, nitrate reduction in the ground, and glacially dominated landscapes and deposits. Potentially, the concept might also be adapted to other specific anthropogenic substances, dominating geochemical processes and geological settings. In addition, the transparency of the SCANVA concept, and the creation of illustrative 2D conceptual models, makes it usable for mediation of results to, e.g. planners and the public in the further process of groundwater protection.

Acknowledgments The presented data and models have been collected and developed in a project collaboration between GEUS and The Danish Nature Agency under the Ministry of Environment and Food.

Open Access This article is distributed under the terms of the Creative Commons Attribution 4.0 International License (http://crea tivecommons.org/licenses/by/4.0/), which permits unrestricted use, distribution, and reproduction in any medium, provided you give appropriate credit to the original author(s) and the source, provide a link to the Creative Commons license, and indicate if changes were made.

\section{References}

Appelo CAJ, Postma D (2005) Geochemistry, groundwater and pollution, 2nd edn. A.A. Balkema Publishers, Rotterdam

Armengol S, Sanchez-Vila X, Folch A (2014) An approach to aquifer vulnerability including uncertainty in a spatial random function framework. J Hydrol 517:889-900. doi:10.1016/j.jhydrol.2014. 06.016

Auken E, Christiansen AV, Westergaard JH et al (2009) An integrated processing scheme for high-resolution airborne electromagnetic surveys, the SkyTEM system. Explor Geophys 40:184. doi:10. 1071/EG08128

Chen SK, Jang CS, Peng YH (2013) Developing a probability-based model of aquifer vulnerability in an agricultural region. J Hydrol 486:494-504. doi:10.1016/j.jhydrol.2013.02.019

Dahl M, Nilsson B, Langhoff JH, Refsgaard JC (2007) Review of classification systems and new multi-scale typology of groundwater-surface water interaction. J Hydrol 344:1-16. doi:10. 1016/j.jhydrol.2007.06.027

Dalgaard T, Hansen B, Hasler B et al (2014) Policies for agricultural nitrogen management-trends, challenges and prospects for improved efficiency in Denmark. Environ Res Lett 9:115002. doi:10.1088/1748-9326/9/11/115002

Danish Economic Councils (2015) Vandrammedirektivet og kvælstofregulering. Grundvand, drikkevand, økonomisk vækst og miljøet (in Danish)

Danish Environmental Portal (2015) http://www.miljoeportal.dk/ 
Danish Environmental Protection Agency (2000) Zonering. Detailkortlægning af arealer til beskyttelse af grundvandsressource (in Danish)

Danish Nature Agency (2014) Redegørelse for Tønder, Løgumkloster m.fl. Afgiftsfinansieret grundvandskortlægning 2014 (in Danish)

Doherty J (2004) PEST: model-independent parameter estimation, 5th edn. Watermark Numerical Computing, Brisbane

European Communities (2008) Groundwater protection in Europe. The new groundwater directive-consolidating the EU regulatory framework

Foster S, Hirata R, Andreo B (2013) The aquifer pollution vulnerability concept: aid or impediment in promoting groundwater protection? Hydrogeol J 21:1389-1392. doi:10.1007/s10040013-1019-7

Gogu RC, Dassargues A (2000) Current trends and future challenges in groundwater vulnerability assessment using overlay and index methods. Environ Geol 39:549-559. doi:10.1007/ s002540050466

Hansen B, Thorling L (2008) Use of geochemistry in groundwater vulnerability mapping in Denmark. Geol Surv Denmark Greenl Bull 15:45-48

Hansen B, Mossin L, Ramsay L et al (2009a) Kemisk grundvandskortlægning Geo-vejledning 6 (in Danish)

Hansen B, Nielsen AM, Holst C, Søndergaard V (2009b) Vurdering af grundvandsmagasiners nitratsårbarhed Geo-vejledning 5 (in Danish)

Hansen B, Thorling L, Dalgaard T, Erlandsen M (2011) Trend reversal of nitrate in Danish groundwater-a reflection of agricultural practices and nitrogen surpluses since 1950. Environ Sci Technol 45:228-234

Hansen B, Dalgaard T, Thorling L et al (2012) Regional analysis of groundwater nitrate concentrations and trends in Denmark in regard to agricultural influence. Biogeosciences 9:3277-3286. doi:10.5194/bg-9-3277-2012

Hansen B, Jørgensen F, Sandersen P, Høyer A-S (2015) Hydrogeokemisk model ved Tønder (in Danish)

Harbaugh AW, Banta ER, Hill MC, McDonald MG (2000) MODFLOW- 2000, The US Geological Survey modular ground-water model: user guide to modularization concepts and the groundwater flow process. US Geol Surv

He XL, Jensen KH, Sonnenborg TO et al (2013) Analyzing the effects of geological and parameter uncertainty on groundwater head and travel time. Hydrol Earth Syst Sci 17:3245-3260. doi:10. 5194/hess-17-3245-2013

Henriksen HJ, Troldborg L, Nyegaard P et al (2003) Methodology for construction, calibration and validation of a national hydrological model for Denmark. J Hydrol 280:52-71

Høyer A-S, Jørgensen F, Foged N et al (2015) Three-dimensional geological modelling of AEM resistivity data-a comparison of three methods. J Appl Geophys 115:65-78. doi:10.1016/j. jappgeo.2015.02.005

I-GIS (2014) http://www.geoscene3d.com

Jørgensen CJ, Jacobsen OS, Elberling B, Aamand J (2009) Microbial oxidation of pyrite coupled to nitrate reduction in anoxic groundwater sediment. Environ Sci Technol 43:4851-4857

Jørgensen F, Høyer A-S, Sandersen PBE et al (2015) Combining 3D geological modelling techniques to address variations in geology, data type and density-an example from Southern
Denmark. Comput Geosci 81:53-63. doi:10.1016/j.cageo.2015. 04.010

Liggett JE, Talwar S (2009) Assessments and integrated water resource management. Streamline Watershed Manag Bull $13: 18-29$

Margat J (1968) Vulnerabilite des nappes d'eau souterraine a la pollution: bases de la cartographie

Postma D, Boesen C, Kristiansen H, Larsen F (1991) Nitrate reduction in an unconfined sandy aquifer-water chemistry, reduction processes, and geochemical modeling. Water Resour Res 27:2027-2045

Rasmussen P, Sonnenborg TO (2015) Grundvandsmodel for kortlægningsområdet Tønder-Løgumkloster (in Danish)

Refsgaard JC, Højberg AL, Møller I et al (2010) Groundwater modeling in integrated water resources management-visions for 2020. Ground Water 48:633-648. doi:10.1111/j.1745-6584. 2009.00634.x

Refsgaard JC, Christensen S, Sonnenborg TO et al (2012) Review of strategies for handling geological uncertainty in groundwater flow and transport modeling. Adv Water Resour 36:36-50. doi:10.1016/j.advwatres.2011.04.006

Sandersen PBE, Jørgensen F (2015) Neotectonic deformation of a Late Weichselian outwash plain by deglaciation-induced fault reactivation of a deep-seated graben structure. Boreas 44:413-431. doi:10.1111/bor.12103

Sinan M, Razack M (2008) An extension to the DRASTIC model to assess groundwater vulnerability to pollution: application to the Haouz aquifer of Marrakech (Morocco). Environ Geol 57:349-363. doi:10.1007/s00254-008-1304-2

Sonnenborg TO, Scharling PB, Hinsby K et al (2015) Aquifer vulnerability assessment based on sequence stratigraphic and 39 Ar transport modeling. Groundwater. doi:10.1111/gwat.12345

Sørensen KI, Auken E (2004) SkyTEM-a new high-resolution main helicopter transient electromagnetic heading system. Explor Geophys 35:191-199

Thomsen R, Søndergaard V (2007) Dense hydrogeological mapping as a basis for establishing groundwater vulnerability maps in Denmark. In: Witkowski AJ, Kowalszyk A, Vrba J (eds) groundwater vulnerability assessment and mapping. Taylor \& Francis, London, pp 33-43

Thomsen R, Søndergaard VH, Sørensen KI (2004) Hydrogeological mapping as a basis for establishing site-specific groundwater protection zones in Denmark. Hydrogeol J 12:550-562. doi:10. 1007/s10040-004-0345-1

Thomsen R, Sondergaard V, Klee P (2013) Greater water security with groundwater. Groundwater mapping and sustainable groundwater management. www.rethinkwater.dk

Van der Veen M, Spitzer R, Green AG, Wild P (2001) Design and application of a towed land-streamer system for cost-effective 2-D and pseudo-3-D shallow seismic data acquisition. Geophysics 66:482-500. doi:10.1190/1.1444939

Viezzoli A, Christiansen AV, Auken E, Sørensen K (2008) Quasi-3D modeling of airborne TEM data by spatially constrained inversion

Vrba J, Zaporožec A (1994) Guidebook on mapping groundwater vulnerability. International contributions to hydrogeology, vol 16. H. Heise, Hannover 